UDK 528.14

\title{
IMPROVEMENT AND EXTENSION OF ETRS 89 IN LATVIA AND LITHUANIA BASED ON THE NKG 2003 GPS CAMPAIGN
}

\author{
Lotti Jivall $^{1}$, Jānis Kaminskis ${ }^{2}$, Eimuntas Paršeliūnas ${ }^{3}$ \\ ${ }^{1}$ Lantmäteriet, SE-801 82 Gävle, Sweden \\ E-mail:lotti.jivall@lm.se \\ ${ }^{2}$ Latvian Geospatial Information Agency, Ojara Vaciesa iela 43, Riga, LV-1004, Latvia \\ E-mail: janis.kaminskis@lgia.gov.lv \\ ${ }^{3}$ Institute of Geodesy, Vilnius Gediminas Technical Uuniversity, \\ Saulètekio al. 11, LT-10223 Vilnius, Lithuania \\ E-mail: eimis@ap.vtu.lt
}

Received 1411 2006, accepted 21122006

\begin{abstract}
The present ETRS 89 realisations in Latvia and Lithuania are based on the EUREF-BAL'92 campaign, which has an estimated accuracy of the same level as the original EUREF 89 campaign (class C). Latvia and Lithuania wish to replace their EUREF-BAL'92 realisation with an ETRS 89 realisation based on the NKG 2003 GPS campaign. The NKG 2003 GPS campaign was carried out in GPS-week 1238 (Sept 28th to Oct 4th 2003) under the framework of the Nordic Geodetic Commission (NKG). The campaign included mainly permanent stations in the Nordic and Baltic area as well as Island, Greenland and Svalbard. In Latvia, Lithuania and Denmark also field sites defining ETRS 89 were included. New ETRS 89 coordinates based on the NKG 2003 campaign have been calculated. The campaign resulted in a set of coordinates in ITRF 2000 epoch 2003.75. All stations in Latvia and Lithuania as well as a sub-set of stations in neighbouring countries were converted to ETRS 89 using the standard procedure described by Boucher and Altamimi. No intraplate deformations have been taken into account, thus the epoch of the ETRS 89 coordinates is 2003.75. Estimated accuracy: 0,5-1 cm (95\%) for the horizontal co-ordinates and 1-2 cm (95\%) for the vertical at the epoch of the observation. The computed ETRS 89 coordinates presented in this paper are to be considered as improvement and extension of ETRS 89 in Latvia and Lithuania based on the NKG 2003 GPS campaign.

During symposia in Riga, 14-17 June 2006, the IAG Reference Frame Sub-commission for Europe (EUREF) recognising, that in Sept-Oct 2003 the EUREF-NKG-2003 campaign in Scandinavia and the Baltic countries was observed, including points in Latvia and Lithuania, and that the results of it were submitted to the EUREF Technical Working Group, where they were accepted as Class B standard (about $1 \mathrm{~cm}$ at the epoch of observation), endorses the subset of points submitted to the EUREF Technical Working Group as extension to the current realisation of ETRS89 (Resolution No 1).
\end{abstract}

Keywords: EUREF, ETRS 89, GPS campaign, ITRF2000.

\section{Introduction}

The present ETRS 89 realisations in Latvia and Lithuania are based on the EUREF-BAL'92 campaign, which has an estimated accuracy of the same level as the original EUREF 89 campaign (class C) [1, 2]. Latvia and Lithuania wish to replace their EUREF-BAL'92 realisation with an ETRS 89 realisation based on the NKG 2003 GPS campaign.

The NKG 2003 GPS campaign was carried out in GPS-week 1238 (Sept $28^{\text {th }}$ to Oct $4^{\text {th }}$ 2003) under the framework of the Nordic Geodetic Commission (NKG). The campaign included mainly permanent stations in the Nordic and Baltic area as well as Island, Greenland and Svalbard. In Latvia, Lithuania and Denmark also field sites defining ETRS 89 were included.
The processing of the campaign is described in [3, 4]. It was presented at the EUREF symposium in Vienna 2005 [3].

\section{Description of the campaign}

GPS observations for the NKG 2003 GPS campaign were carried out from Sept 28th to Oct 4th, 2003 (day 271 to 277, GPS-week 1238) [4]. The observation campaign was co-ordinated by Finn Bo Madsen at KMS, Denmark. Stations from Denmark, Estonia, Finland, Greenland, Iceland, Latvia, Lithuania, Norway and Sweden - in total 133 stations - participated in the campaign (Figs 1, 2).

The equipment used at the Latvian and Lithuanian stations is reported in Tables 1, 2 . 
The Lithuanian observers raised problems with one of their stations (L311). Thus this station was observed for 5 extra days (292-296), 10 days after the campaign together with the Lithuanian stations VLNS and KLPD.

Data and sitelog information for all stations have been transferred to an ftp-server at KMS in Copenhagen.

The RINEX-files and site log files were checked for quality, completeness and correctness by Henrik Rønnest at KMS. This quality control is documented in a special Data Validation Report.

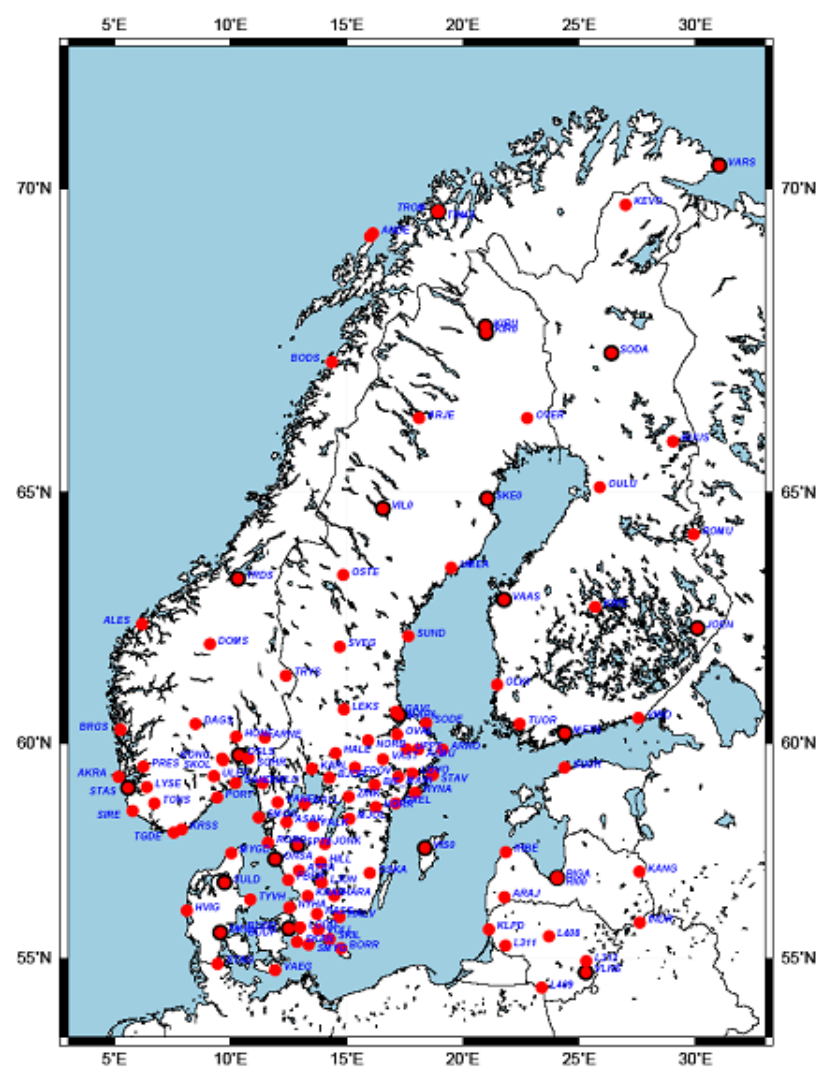

Fig 1. Stations in the Nordic-Baltic part of the NKG 2003 campaign

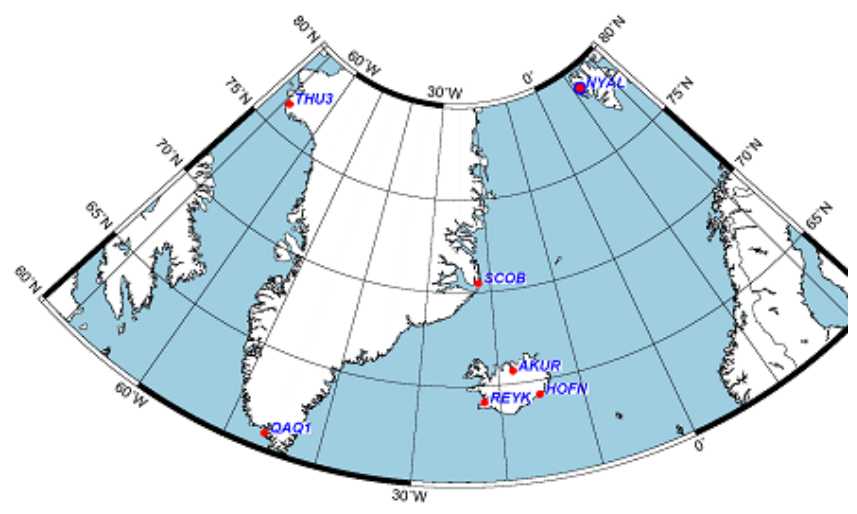

Fig 2. Stations in the Atlantic part of the NKG 2003 campaign
Table 1. Equipment used in Latvia

\begin{tabular}{|l|c|l|c|}
\hline Station & \multicolumn{1}{|c|}{ Antenna } & \multicolumn{1}{|c|}{ Receiver } & $\boldsymbol{H}$ \\
\hline ARAJ & TRM33429.00+GP & $\begin{array}{l}\text { TRIMBLE } \\
4700\end{array}$ & 1,5561 \\
\hline INDR & TRM33429.00+GP & $\begin{array}{l}\text { TRIMBLE } \\
4700\end{array}$ & 1,5759 \\
\hline IRBE & ASH700936D_M & $\begin{array}{l}\text { TRIMBLE } \\
4000 S S E\end{array}$ & 5,1115 \\
\hline KANG & TRM33429.00+GP & $\begin{array}{l}\text { TRIMBLE } \\
4700\end{array}$ & 1,4089 \\
\hline RI00 & TRM22020.00+GP & $\begin{array}{l}\text { TRIMBLE } \\
4000 S S E\end{array}$ & 1,3633 \\
\hline RIGA & ASH700936D_M & $\begin{array}{l}\text { ROGUE } \\
\text { SNR-8000 }\end{array}$ & 0,0850 \\
\hline
\end{tabular}

Table 2. Equipment used in Lithuania

\begin{tabular}{|l|l|l|c|}
\hline Station & \multicolumn{1}{|c|}{ Antenna } & Receiver & $\boldsymbol{H}$ \\
\hline KLPD & ASH700936E & ASHTECH Z-XII3 & 0,0000 \\
\hline L311 & ASH701008.01B & ASHTECH UZ-12 & 1,7700 \\
\hline L312 & ASH700228D & ASHTECH Z-XII3 & 1,6513 \\
\hline L408 & ASH701008.01B & ASHTECH UZ-12 & 1,6760 \\
\hline L409 & ASH701008.01B & ASHTECH UZ-12 & 1,7503 \\
\hline VLNS & ASH700936A_M & ASHTECH Z-XII3 & 0,0730 \\
\hline
\end{tabular}

\section{Processing strategy}

The GPS campaign was processed by different software packages available within the group [3, 4]. These are:

Norway: NMA - GIPSY,

Sweden: OSO - GAMIT/GLOBK ,

Sweden: LMV - Bernese ver 5.0,

Denmark: KMS - Bernese ver 4.2.

As a general philosophy for computing a GPS campaign using different software packages, we have concluded that each software package should be used together with the recommended settings for the respective software. Using this approach, we will be able to check for possible differences in the result not only depending on the programmes used, but also due to differences in processing strategy. No attempt is therefore made to fully harmonise the processing strategy.

Thus guidelines/common settings are:

Use recommended settings for each programme,

10 deg cut-off angle,

Elevation-dependent weighting,

Niell mapping function for tropospheric corrections,

Common ocean tide loading (FES 99),

No atmospheric loading corrections,

Antenna $p c v$ from IGS, if available,

Final IGS orbits and clocks (if possible),

Sub-division of the network not necessary,

ITRF 2000, epoch of the campaign (2003.75). 


\section{Internal results}

The internal results of the four individual solutions were evaluated in terms of the ambiguity resolution and the RMS of daily repeatability. The NMA solution is a pure float solution, ie no attempt to resolve ambiguities has been performed. The other three solutions are fixed solutions, where those ambiguities that could be reliable resolved are fixed to integer values. The success rate of resolved ambiguities are not reported for the OSO solution, the LMV and KMS solutions have $88 \%$ and $66 \%$, respectively. The daily repeatability expressed in RMS values is for all solutions a few $\mathrm{mm}$ in North and East and up to $1 \mathrm{~cm}$ in height. The daily repeatability for a subset of stations in one of the solutions (LMV) is shown in Fig 3.

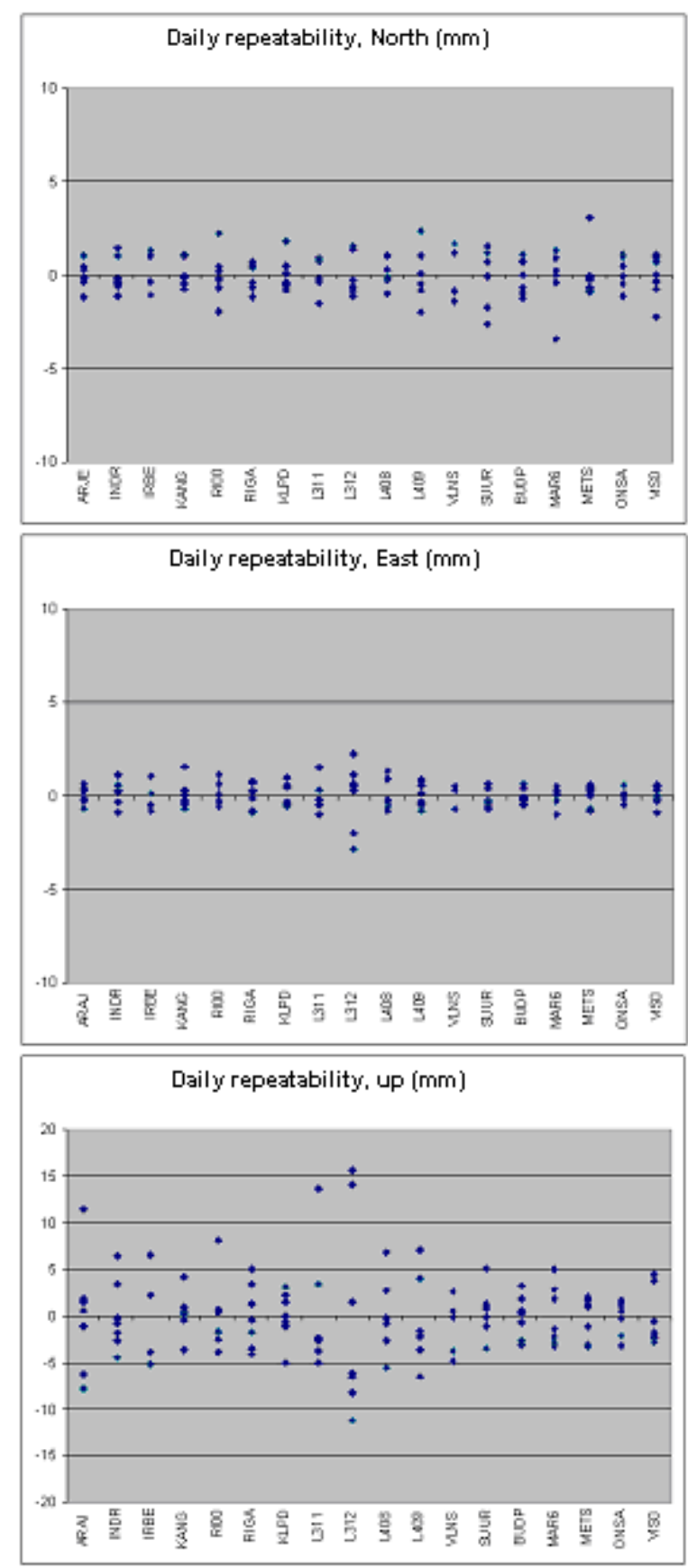

Fig 3. Daily repeatability (LMV solution)
The connection to ITRF 2000 was made in different ways. The NMA solution (based on GIPSY/OASISII) used so-called X-files from JPL (daily 7 Helmert transformation parameters determined from a global fit to ITRF 2000). Also, the OSO solution is globally connected to ITRF by solving for 7 Helmert parameters. The two Bernese solutions (LMV and KMS) are both regionally connected to ITRF 2000 by setting up a no translation condition to a set of reference stations in the area. Table 3.

The characteristics of 4 solutions are summarised in

Table 3. Four different solutions

\begin{tabular}{|l|l|l|l|}
\hline AC & Software & Ambiguities & ITRF connection \\
\hline NMA & GIPSY & Float & $\begin{array}{l}\text { Global } \\
7 \text { parameters }\end{array}$ \\
\hline OSO & GAMIT & Fixed & $\begin{array}{l}\text { Global } \\
7 \text { parameters }\end{array}$ \\
\hline LMV & $\begin{array}{l}\text { Bernese } \\
5.0\end{array}$ & Fixed (88 \%) & $\begin{array}{l}\text { Regional } \\
\text { 3 parameters }\end{array}$ \\
\hline KMS & $\begin{array}{l}\text { Bernese } \\
4.2\end{array}$ & Fixed (66 \%) & $\begin{array}{l}\text { Regional } \\
3 \text { parameters }\end{array}$ \\
\hline
\end{tabular}

\section{Combination of the 4 solutions}

The 4 individual solutions were compared to each other. The following RMS values turned out from a first direct comparison: 1,4, 1,5 and 4,7 mm for North, East and up. There are shifts between the solutions, eg OSO is 2-3 mm South-East of the other solutions and LMV and KMS are ca 5-10 mm below OSO and NMA. The differences depend mainly on different approaches for connection to ITRF 2000.

To eliminate the differences depending on the different ITRF connections, it was decided to harmonise them by transforming all solutions to the average of the two global solutions (NMA and OSO) (Fig 4).

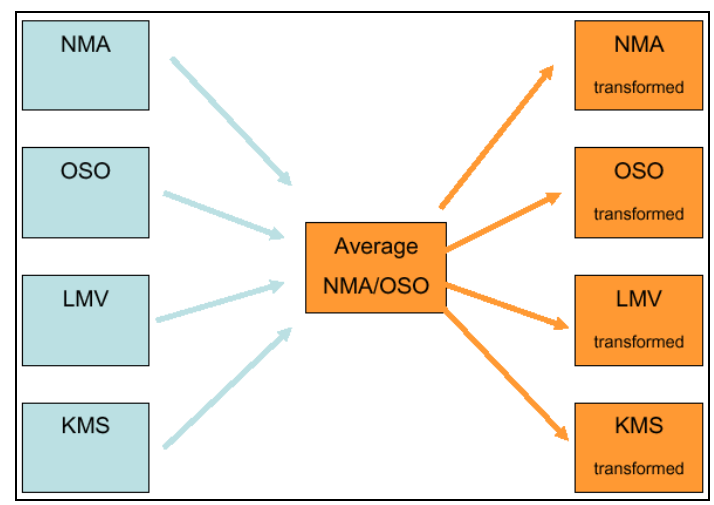

Fig 4. Harmonising the solutions (L. Jivall, S/LMV)

The 4 solutions transformed to the averaged NMA/OSO solution were compared to each other. Residuals from the mean are presented in Fig 5. 

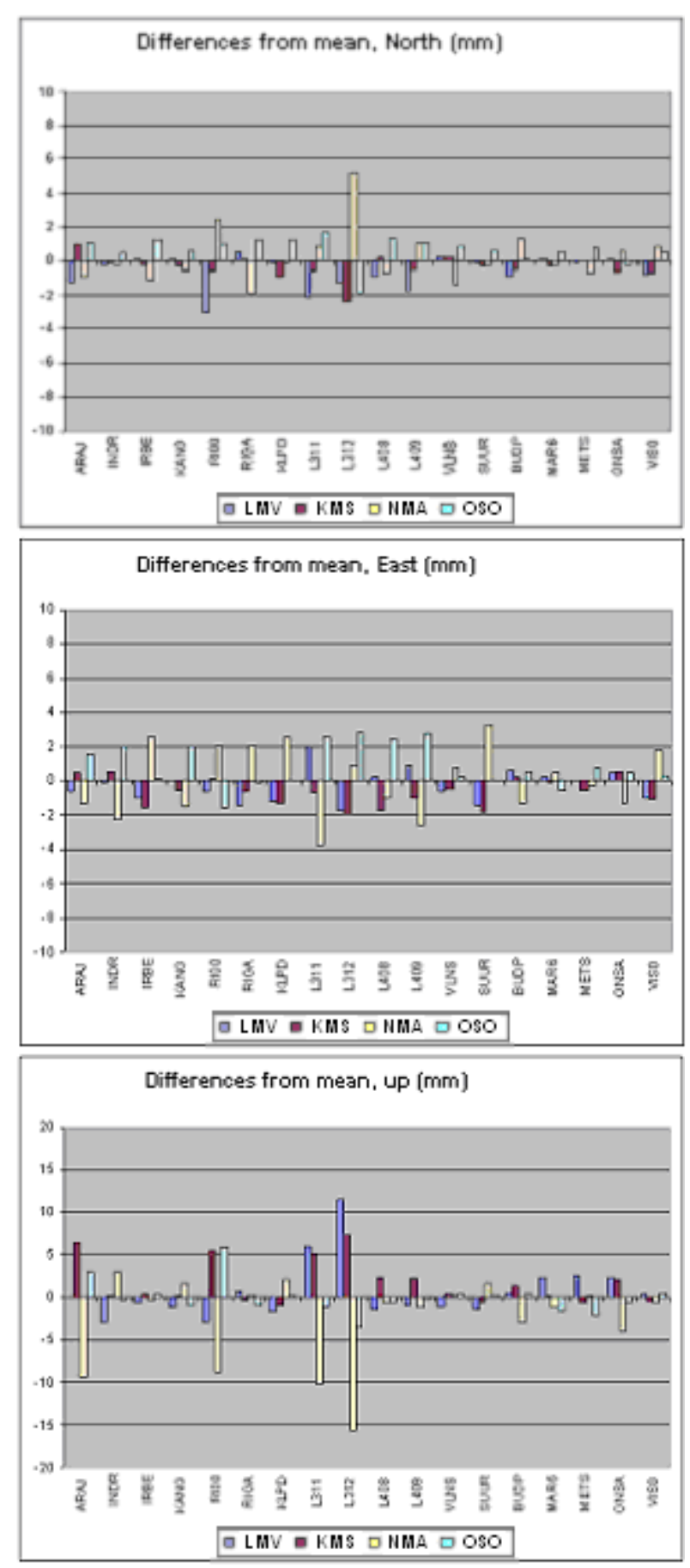

Fig 5. Comparison between harmonised solutions

The differences are after this harmonisation generally very small and the systematic effects seen before have (almost) disappeared. (Some small systematic effects in height are left.) The RMS values of all differences in each component are 0,9, 1,2 and 2,5 mm (North, East and up), which should be compared to the corresponding values before harmonisation $(1,4,1,5$ and $4,7 \mathrm{~mm})$. Especially in height there is a large improvement. Just $7 \%, 17 \%$ and $11 \%$ of the stations have residuals larger than $2 \mathrm{~mm}$ in the North, $2 \mathrm{~mm}$ in the East and $5 \mathrm{~mm}$ in up, respectively. The final combined solution of the NKG 2003 campaign is the average of the 4 harmonised solutions (Fig 6). 7-parameter

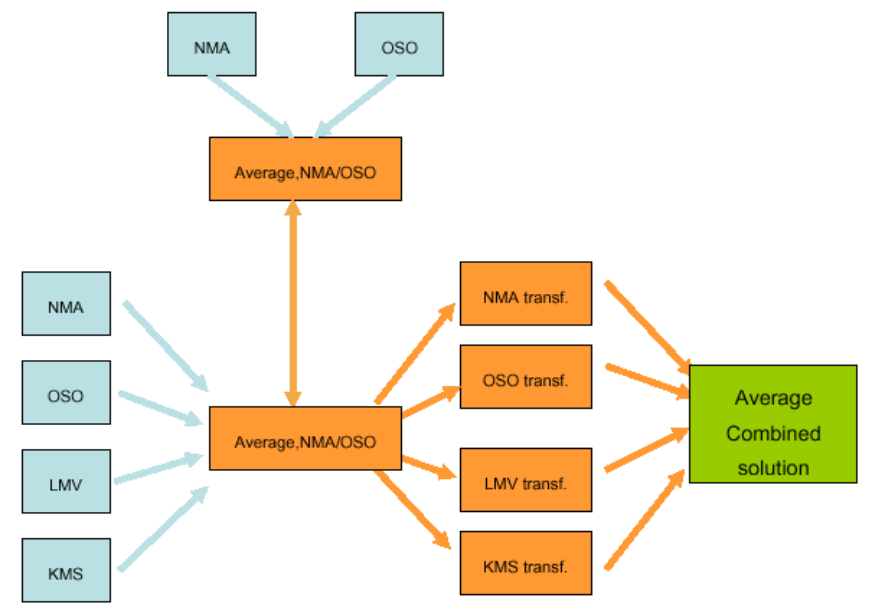

Fig 6. Scheme of the combined solution

transformations have been used for the transformation to the averaged NMA/OSO-solution.

The accuracy estimation for the final solution is based on the following components (values on $95 \%$ level):

Accuracy of the ITRF connection (few $\mathrm{mm}$ in horizontal, $1 \mathrm{~cm}$ in height),

Systematic effects depending on un-modelled errors or wrong models (few $\mathrm{mm}$ in horizontal, $0,5-1 \mathrm{~cm}$ in height),

Random errors, noise in the solutions (few mm both in horizontal and height with some exceptions).

Alltogether this gives $0,5-1 \mathrm{~cm}$ in the horizontal and 1-2 cm in the vertical on $95 \%$-level for the main part of stations (eg ANDO and L312 might be less accurate in height).

Final combined geodetic coordinates in ITRF2000 epoch 2003.75 are presented in [4].

\section{Transformation to ETRS 89}

The final coordinates of the NKG 2003 campaign in ITRF 2000 epoch 2003.75 was converted to ETRS 89 according to the guidelines in [5]. The last step, which is to take the velocities within the European plate into account, has not been performed, which means that we ended up with a realisation of ETRS 89 in epoch 2003.75 .

To reduce the internal deformations to epoch 1989.0 was never in question, since this would just increase the gap to the neighbouring ETRS 89 realisations, which where not reduced for the internal velocities.

A reduction to epoch 2000.0 was considered but the arguments against it were stronger. The most important arguments are that the largest influence will be in the vertical component which is not so well determined in existing ETRS89 realisations anyway, and that for the future it may be difficult to track which corrections that have been applied since this is not a standard way to proceed. A test was performed to reduce for the intraplate deformations to epoch 2000.0 anyway (Table 4). The NKG_RF03vel velocity field was used for this reduction [6].

Conclusion is that the differences are so small for 
Table 4. NKG 2003 (2003.75) minus NKG 2003 (2000.0)

\begin{tabular}{|l|l|l|l|}
\hline Point & $\boldsymbol{N}, \mathbf{m m}$ & $\boldsymbol{E}, \mathbf{m m}$ & $\boldsymbol{U}, \mathbf{~ m m}$ \\
\hline ARAJ & $-1,8$ & $-0,1$ & 3,1 \\
\hline INDR & $-1,2$ & $-0,4$ & 0,0 \\
\hline IRBE & $-2,7$ & 0,6 & 6,6 \\
\hline KANG & $-1,8$ & 0,2 & 1,7 \\
\hline RI00 & $-2,0$ & 0,4 & 3,1 \\
\hline RIGA & $-2,0$ & 0,4 & 3,1 \\
\hline KLPD & $-1,5$ & $-0,3$ & 1,8 \\
\hline L311 & $-1,2$ & $-0,6$ & 0,8 \\
\hline L312 & $-0,6$ & $-0,7$ & $-0,9$ \\
\hline L408 & $-1,4$ & $-0,6$ & 0,4 \\
\hline L409 & $-0,5$ & $-0,7$ & $-1,3$ \\
\hline VLNS & $-0,9$ & $-0,8$ & $-1,2$ \\
\hline
\end{tabular}

the new stations, so it is better to stay in the internal epoch of the campaign.

The following model and parameters were used for the conversion:

$$
\begin{aligned}
& X_{E}(2003.75)=X_{00}(2003.75)+\left[\begin{array}{c}
T 1_{00} \\
T 2_{00} \\
T 3_{00}
\end{array}\right]+ \\
& {\left[\begin{array}{ccc}
0 & -\dot{R} 3_{00} & R \dot{2}_{00} \\
R \dot{3}_{00} & 0 & -\dot{R} 1_{00} \\
-\dot{R} 2_{00} & R \dot{1}_{00} & 0
\end{array}\right] \cdot X_{00}(2003.75) \times}
\end{aligned}
$$

$(2003.75-1989.0)$ here

$X_{E}(2003,75)-$ coordinates in ETRS 89 at epoch 2003,75 ,

$X_{00}(2003,75)$ - coordinates in ITRF2000 at epoch 2003,75 ,

$$
\begin{aligned}
& T 1_{00}=5,4 \mathrm{~cm}, \\
& T 2_{00}=5,1 \mathrm{~cm}, \\
& T 3_{00}=-4,8 \mathrm{~cm}, \\
& R \dot{1}_{00}=0,000081^{\prime \prime} / Y, \\
& R \dot{2}_{00}=0,000490^{\prime \prime} / Y, \\
& R \dot{3}_{00}=-0,000792^{\prime \prime} / Y .
\end{aligned}
$$

Final coordinates in ETRS 89 epoch 2003.75 are

\begin{tabular}{|c|c|c|c|c|c|c|c|c|c|c|}
\hline Station & $\boldsymbol{X}$ & $Y$ & $Z$ & \multicolumn{3}{|c|}{ Latitude } & \multicolumn{3}{|c|}{ Longitude } & Height \\
\hline ARAJ & 3277266,901 & 1309685,665 & 5295146,602 & 56 & 29 & 36,583375 & 21 & 46 & 58,8127 & 208,5617 \\
\hline INDR & 3177703,862 & 1662049,956 & 5257080,228 & 55 & 52 & 44,774145 & 27 & 36 & 40,09091 & 213,6403 \\
\hline IRBE & 3183612,378 & 1276706,499 & 5359310,711 & 57 & 33 & 15,896995 & 21 & 51 & 7,177188 & 40,6837 \\
\hline KANG & 3078175,306 & 1608797,614 & 5331767,505 & 57 & 5 & 40,532341 & 27 & 35 & 37,1829 & 163,8277 \\
\hline RI00 & 3183914,380 & 1421473,491 & 5322796,718 & 56 & 56 & 54,462143 & 24 & 3 & 30,94915 & 29,3677 \\
\hline RIGA & 3183899,552 & 1421478,321 & 5322810,644 & 56 & 56 & 55,021188 & 24 & 3 & 31,56767 & 34,7296 \\
\hline KLPD & 3359228,479 & 1297490,297 & 5246690,181 & 55 & 42 & 55,269141 & 21 & 7 & 7,968095 & 42,7467 \\
\hline L311 & 3376643,347 & 1352769,794 & 5221718,728 & 55 & 19 & 6,736029 & 21 & 49 & 56,29229 & 92,5081 \\
\hline L312 & 3320254,356 & 1570665,037 & 5197158,071 & 54 & 55 & 51,389147 & 25 & 19 & 0,314766 & 229,5565 \\
\hline L408 & 3311606,955 & 1453968,652 & 5236111,119 & 55 & 32 & 44,811092 & 23 & 42 & 14,35198 & 138,3876 \\
\hline L409 & 3425868,215 & 1482315,546 & 5154672,319 & 54 & 16 & 19,514616 & 23 & 23 & 50,3639 & 228,4221 \\
\hline VLNS & 3343600,978 & 1580417,560 & 5179337,131 & 54 & 39 & 11,305031 & 25 & 17 & 55,19055 & 240,8512 \\
\hline SUUR & 2959056,722 & 1341058,359 & 5470427,147 & 59 & 27 & 48,87703 & 24 & 22 & 48,92238 & 84,3815 \\
\hline METS & 2892571,140 & 1311843,288 & 5512633,987 & 60 & 13 & 2,890212 & 24 & 23 & 43,13437 & 94,6124 \\
\hline TUOR & 2917811,098 & 1205222,559 & 5523549,965 & 60 & 24 & 57,047803 & 22 & 26 & 36,31039 & 60,6023 \\
\hline VIRO & 2788248,528 & 1454873,328 & 5530280,044 & 60 & 32 & 19,674328 & 27 & 33 & 17,96948 & 36,9679 \\
\hline HASS & 3464655,861 & 845749,9609 & 5270271,527 & 56 & 5 & 31,973643 & 13 & 43 & 5,062868 & 114,0531 \\
\hline NORR & 3199093,348 & 932231,3078 & 5420322,525 & 58 & 35 & 24,824117 & 16 & 14 & 46,96321 & 40,9661 \\
\hline OSKA & 3341340,210 & 957912,3193 & 5330003,248 & 57 & 3 & 56,291554 & 15 & 59 & 48,50215 & 149,7949 \\
\hline VISO & 3246470,583 & 1077900,333 & 5365277,931 & 57 & 39 & 13,921952 & 18 & 22 & 2,325085 & 79,8165 \\
\hline BUDD & 3513649,635 & 778954,5593 & 5248201,786 & 55 & 44 & 19,917329 & 12 & 29 & 59,84271 & 87,9513 \\
\hline VAEG & 3612855,262 & 763382,2592 & 5183133,645 & 54 & 42 & 51,917575 & 11 & 55 & 51,18784 & 60,552 \\
\hline BOR1 & 3738358,781 & 1148173,505 & 5021815,591 & 52 & 16 & 37,034356 & 17 & 4 & 24,42773 & 124,3743 \\
\hline JOZE & 3664940,515 & 1409153,668 & 5009571,223 & 52 & 5 & 50,179962 & 21 & 1 & 53,52356 & 141,4658 \\
\hline LAMA & 3524523,262 & 1329693,437 & 5129846,172 & 53 & 53 & 32,630708 & 20 & 40 & 11,77439 & 187,0278 \\
\hline POTS & 3800689,947 & 882077,1757 & 5028791,132 & 52 & 22 & 45,46029 & 13 & 3 & 57,91419 & 144,4271 \\
\hline WROC & 3835751,626 & 1177249,752 & 4941605,058 & 51 & 6 & 47,729275 & 17 & 3 & 43,32962 & 180,8227 \\
\hline
\end{tabular}
given both expressed as geocentric Cartesian coordinates and geodetic ellipsoidal coordinates (Table 5).

\section{Comparison to other ETRS 89 realisations}

The above computed ETRS 89 coordinates from the NKG2003 campaign was compared to previous ETRS 89 realisations in or close to Latvia and Lithuania.

Table 5. Geodetic coordinates in ETRS 89 epoch 2003.75 (based on ITRF 2000) for a subset of the NKG2003 campaign 
The campaign did not include any stations in Poland, but one of the analysis centres (using Gamit) has included permanent stations also in Poland in their solution (and other permanent stations in Northern Europe). Treating these coordinates in the same way, ie transforming to the average of the Gipsy and Gamit solutions, we have got some Polish stations in the NKG 2003 solution that could be used for test of the consistency of ETRS 89 in the area.

\section{EUREF-BAL'92}

The EUREF-BAL'92 campaign was carried out from Aug 29 to Sept 4, 1992. Two sessions of 5 hours were observed each day. The processing was performed as a classical densification of the original EUREF 89 campaign [1]. Differences to the EUREF-BAL'92 coordinates are presented in Table 6.

Table 6. ETRS 89 based on NKG 2003 minus EUREF-BAL'92 [1]

\begin{tabular}{|l|r|r|r|}
\hline Point & $\boldsymbol{N}, \mathbf{~ m m}$ & $\boldsymbol{E}, \mathbf{~ m m}$ & $\boldsymbol{U}, \mathbf{~ m m}$ \\
\hline ARAJ & $-3,7$ & $-37,2$ & $-42,7$ \\
\hline INDR & 16,8 & $-83,3$ & 15,3 \\
\hline KANG & 6,5 & $-46,7$ & $-24,7$ \\
\hline RI00 & $-9,1$ & $-27,9$ & 30,3 \\
\hline L311 & 13,5 & $-16,4$ & 30,7 \\
\hline L312 & 28,0 & $-25,9$ & 42,6 \\
\hline L408 & 5,7 & $-9,4$ & 18,8 \\
\hline L409 & 19,3 & 7,4 & 34,9 \\
\hline RMS & 16,0 & 40,3 & 33,6 \\
\hline
\end{tabular}

At INDR coordinates of a mark 0252 were used. This mark was observed by Defense Mapping Agency (USA) during GPS campaign in the period from Aug 24 till Sept 3, 1993. In the course of these works, it was stated that the point observed in 1992 (project No 0407) and in 1993 (project No 0252) are not identical, but are located close to each other. At present, only the historical geodetic mark No 0252 exists on the site Indra.

Another adjustment of EUREF-BAL'92 campaign was performed by W. Ehrnsperger [2]. Differences in this solution are presented in Table 7.

Table 7. ETRS 89 based on NKG 2003 minus EUREF-BAL'92 [2]

\begin{tabular}{|l|r|r|r|}
\hline Point & $\boldsymbol{N}, \mathbf{~ m m}$ & \multicolumn{1}{c|}{$\mathbf{~ m m}$} & $\boldsymbol{U}, \mathbf{~ m m}$ \\
\hline ARAJ & $-20,5$ & $-17,0$ & 19,7 \\
\hline KANG & $-29,7$ & $-7,7$ & $-5,3$ \\
\hline RI00 & $-17,8$ & $-0,6$ & 40,7 \\
\hline L311 & 0,0 & 0,0 & 44,1 \\
\hline L312 & $-12,4$ & $-20,6$ & 40,5 \\
\hline L408 & $-22,7$ & 13,3 & 19,6 \\
\hline L409 & 22,0 & $-11,8$ & 28,1 \\
\hline RMS & 21,5 & 13,5 & 33,7 \\
\hline
\end{tabular}

All stations agree with the expected accuracy level of the EUREF-BAL'92 campaign.

\section{EUREF-POL'1992}

The EUREF-POL 1992 campaign was performed on July 4-8, 1992. Four days with 10,5 hours session and one with 4 hours. The solution is based on ITRF 91 [7]. Differences are presented in Table 8.

Table 8. ETRS 89 based on NKG 2003 minus EUREF-POL'92

\begin{tabular}{|l|r|r|r|}
\hline Point & \multicolumn{1}{|c|}{$\mathbf{~ m m}$} & \multicolumn{1}{c|}{$\mathbf{~ m m}$} & $\boldsymbol{U}, \mathbf{~ m m}$ \\
\hline RI00 & $-27,1$ & $-4,7$ & 24,0 \\
\hline L311 & 1,7 & $-8,2$ & $-1,2$ \\
\hline L312 & $-8,8$ & $-25,3$ & 31,9 \\
\hline JOZE & 14,7 & $-5,2$ & 10,8 \\
\hline RMS & 18,5 & 15,9 & 23,9 \\
\hline
\end{tabular}

The difference in antenna height between the two campaigns $(198 \mathrm{~mm})$ at JOZE has been taken into account. The differences are on an expected level.

\section{EUREF-POL'2001}

The EUREF-POL'2001 was performed five 24-hour sessions during Sept 2001 as a quality check of the Polish part of the EUREF-POL'1992 campaign. The solution was computed in ITRF 2000 and then aligned to the EUREF-POL'1992 campaign by a 7-parametertransformation [8]. (Conversion to ETRS 89 by the standard procedure was also performed and it resulted in differences of 1-2 $\mathrm{cm}$ level to the published coordinates stemming from the local 7-parameter transformation. If these differences are corrected, the horizontal components agree within $5 \mathrm{~mm}$, but in height there will be ca $2 \mathrm{~cm}$ difference). Differences are presented in Table 9.

Table 9. ETRS 89 based on NKG 2003 minus EUREFPOL'2001

\begin{tabular}{|l|r|r|r|}
\hline Point & $\boldsymbol{N}, \mathbf{~ m m}$ & $\boldsymbol{E}, \mathbf{~ m m}$ & $\boldsymbol{U}, \mathbf{~ m m}$ \\
\hline BOR1 & 7,3 & $-5,0$ & $-17,1$ \\
\hline JOZE & 0,2 & $-17,6$ & 0,5 \\
\hline LAMA & $-5,4$ & $-9,6$ & $-1,4$ \\
\hline WROC & 8,2 & $-7,4$ & $-3,9$ \\
\hline RMS & 7,1 & 12,7 & 10,2 \\
\hline
\end{tabular}

\section{SWEREF 99}

SWEREF 99 - Swedish ETRS 89 is based on 6 weeks of data during summer 1999 on permanent stations in Sweden, Denmark, Finland and Norway. The solution was computed in ITRF 97 and reduced to ETRS 89 with the standard procedure without taking the internal velocities in the European plate into account [9]. Four stations close to Latvia and Lithuania have been compared to the ETRS 89 realisation of NKG 2003. Differences are presented in Table 10. 
Table 10. ETRS 89 based on NKG 2003 minus SWEREF 99

\begin{tabular}{|c|c|c|c|}
\hline Point & $\mathrm{N}, \mathrm{mm}$ & $E, \mathrm{~mm}$ & $\boldsymbol{U}, \mathrm{mm}$ \\
\hline HASS & $-2,9$ & 7,7 & 37,7 \\
\hline NORR & $-4,4$ & 12,8 & 49,6 \\
\hline OSKA & $-4,4$ & 11,2 & 42,2 \\
\hline VISO & $-6,3$ & 12,9 & 38,0 \\
\hline RMS & 5,4 & 13,1 & 48,7 \\
\hline
\end{tabular}

\section{EUREF-FIN-96/97}

The EUREF FIN-96/97 is based on GPS-campaigns during the years 1996 and 1997. 23 weeks of data on the permanent stations were used. The solution was computed in ITRF 96 and reduced to ETRS 89 with the standard procedure without taking the internal velocities in the European plate into account [10]. Three stations close to Latvia and Lithuania have been compared to the ETRS 89 realisation of NKG 2003. Differences are in Table 11.

Table 11. ETRS 89 based on NKG 2003 minus EUREF-FIN-96/97

\begin{tabular}{|l|r|r|r|}
\hline Point & $\boldsymbol{N}, \mathbf{~ m m}$ & $\boldsymbol{E}, \mathbf{~ m m}$ & $\boldsymbol{U}, \mathbf{~ m m}$ \\
\hline METS & $-7,8$ & 15,3 & 44,7 \\
\hline TUOR & $-9,6$ & 13,6 & 50,3 \\
\hline VIRO & $-11,4$ & 14,1 & 45,2 \\
\hline RMS & 11,9 & 17,6 & 57,3 \\
\hline
\end{tabular}

\section{EUREF-DK94}

The EUREF-DK94 campaign was observed from Aug 29 to Sept 2, 1994. The solution was computed in ITRF 92 and converted to ETRS 89 with the standard procedure without taking the internal velocities in the European plate into account [11]. Differences are in Table 12.

Table 12. ETRS 89 based on NKG 2003 minus EUREF-DK94

\begin{tabular}{|l|r|r|r|}
\hline Point & $\boldsymbol{N}, \mathbf{~ m m}$ & $\boldsymbol{E}, \mathbf{~ m m}$ & $\boldsymbol{U}, \mathbf{m m}$ \\
\hline BUDD & $-5,0$ & 20,2 & 5,9 \\
\hline VAEG & 2,5 & 14,8 & 4,7 \\
\hline RMS & 5,6 & 25,0 & 7,6 \\
\hline
\end{tabular}

\section{General comments on the differences}

Large differences in height for the comparisons to Estonia, Sweden and Finland depend to a large extent on the land up-lift. Note that the land up-lift is larger in those countries than in Latvia and Lithuania (Table 4). Another important reason for the systematic differences (especially in the East component) between the ETRS 89 realisations is that different velocity models for the European plate motion (Nuvel $1 A$ and ITRF 2000) have been used for the reduction to epoch 1989.0.

\section{Conclusions}

1. New ETRS 89 coordinates based on the NKG 2003 campaign have been calculated. The campaign resulted in a set of coordinates in ITRF 2000 epoch 2003.75. All stations in Latvia and Lithuania as well as a sub-set of stations in neighbouring countries were converted to ETRS 89 using the standard procedure described by Boucher and Altamimi. No intraplate deformations have been taken into account, so the epoch of the ETRS 89 coordinates is 2003.75 .

2. The ITRF 2000 solution of the NKG 2003 campaign is used as a node in the transformation between the Nordic national ETRS 89 realisations. Choosing this solution for the basis of the Latvian and Lithuanian ETRS 89 realisation, give a direct link to the Nordic ETRS 89 realisations.

3. Estimated accuracy: $0,5-1 \mathrm{~cm}(95 \%)$ for the horizontal co-ordinates and $1-2 \mathrm{~cm}(95 \%)$ for the vertical at the epoch of the observation.

4. During symposia in Riga, 14-17 June 2006, the IAG Reference Frame Sub-commission for Europe (EUREF) recognising, that in Sept-Oct 2003 the EUREF-NKG-2003 campaign in Scandinavia and the Baltic countries was observed, including points in Latvia and Lithuania, and that the results of it were submitted to the EUREF Technical Working Group, where they were accepted as Class B standard (about $1 \mathrm{~cm}$ at the epoch of observation), endorses the subset of points submitted to the EUREF Technical Working Group as extensions to the current realisation of ETRS 89 (Resolution No 1).

\section{Acknowledgement}

The authors express their great acknowledgement to NKG and to all colleagues who have participated in the field measurements and in computations of the campaign.

\section{References}

1. MADSEN, F.; MADSEN, B. A new GPS-network in the Baltic Countries. In Report on the Symposium of the IAG Subcommission for Europe (EUREF) held in Budapest, 17-19 May 1993, p. 83-91.

2. EHRNSPERGER, W. Adjustment of the 1992 - GPS Network in the Baltic countries. In Report on the Symposium of the IAG Subcommission for Europe (EUREF) held in Helsinki, 3-6 May 1995, p. 282-292.

3. JIVALL, L. et al. Processing the NKG 2003 GPS Campaign. In Report on the Symposium of the IAG Subcommission for Europe (EUREF) held in Vienna, 1-3 June 2005 (draft).

4. JIVALL, L. et al. Processing of the NKG 2003 GPS Campaign. In Reports in Geodesy and Geographical Information Systems. Lantmäteriet, Sweden: LMV-rapport 2005:7. 104 p. (www.nkg.fi/posref.html).

5. BOUCHER, C.; ALTAMIMI, Z. Specifications for Reference Frame Fixing in the Analysis of a EUREF GPS Campaign, version 5.0 (2001-12-04), 2001. 7 p.

6. LIDBERG, M.; JOHANSSON, J. Geodetic reference frames in the presence of crustal deformations. In Report on the Symposium of the IAG Subcommission for Europe (EUREF) held in Riga, 14-17 June 2006 (draft). 
7. ZIELINSKI, J. B. et al. Final report about the EUREFPOL' 1992 GPS Campaign. In Report on the Symposium of the IAG Subcommission for Europe (EUREF) held in Warsaw, 8-11 June 1994, p. 92-99.

8. JAWORSKI, L. et al. Results of the EUREF-POL'2001 GPS Campaign. In Report on the Symposium of the IAG Subcommission for Europe (EUREF) held in Ponta del Gada, 5-8 June 2002, p. 185-198.

9. JIVALL, L.; LIDBERG, M. SWEREF 99 - an Updated EUREF Realisation for Sweden. In Report on the Symposium of the IAG Subcommission for Europe (EUREF) held in Troms $\varnothing$, 22-24 June 2000, p. 167-175.

10. OLLIKAINEN, M.; KOIVULA, A.; POUTANEN, M. The Densification of the EUREF Network in Finland. In Report on the Symposium of the IAG Subcommission for Europe (EUREF) held in Prague, 2-5 June 1999, p. 114122.

11. FANKHAUSER, S.; GURTNER, W. Denmark EUREF Densification Campaign EUREF-DK94. In Report on the Symposium of the IAG Subcommission for Europe (EUREF) held in Helsinki, 3-6 May 1995, p. 36.
Lotti Jivall. Research geodesist. National Land Survey of Sweden (Lantmäteriet), SE-80182 Gävle, Sweden. $\mathrm{Ph}+46(0) 26633740$.

Msc (1987) Royal Institute of Technology, Stockholm, Sweden. Author of more than 30 technical reports and scientific papers. Participated in 3 NKG Summer/Autumn schools for researchers in geodesy. Participated in many intern conferences.

Research interests: Global Navigation Satellite Systems, geodetic reference frames.

Jānis Kaminskis. Director of Geodesy Dept, Latvian Geospatial Information Agency, Ojara Vaciesa iela 43, Riga, LV-1004, Latvia. Ph +371 706 4200, Fax +371 7064211.

MSc (1995). Author of more than 10 scientific papers. Participated in many intern conferences. Training at the Finnish Geodetic Institute in 1994, National Survey and Cadastre (KMS) and Copenhagen University in 1995/96.

Research interests: geodesy, adjustment of geodetic networks, gravity field modelling.

Eimuntas Paršeliūnas. Associate Professor, Doctor. Vilnius Gediminas Technical University. Dept of Geodesy and Cadastre. Ph +370 5274 4703, Fax +370 52744705 .

Doctor (1992). Author of two teaching books and more than 40 scientific papers. Participated in many intern conferences.

Research interests: graphs theory in geodesy, adjustment of geodetic networks, geoinformation systems. 